European-American Consensus Group (EACG) criteria. Statistical analysis was performed using the SPSS vs.20 package

Results: 348 patients (331 women), mean age at diagnosis $56.12 \pm 14.19$ years (range 22-92), with possible SS were analysed. All patients met the European criteria for SS diagnosis, and 242 the EACG criteria. AAN were positive in 345 (99.4\%) patients, RF in 169 (48.4\%), anti-Ro60/SSA in188 (54\%), and anti-La/ SSB in 11 (32\%). Anti-Ro52 abs. were positive in 173 (49.7\%) patients: 162 women, 11 men. Of these patients, 154 (89\%) also had anti-Ro60/SSA positive abs., 103 (59.5\%) anti-La/SSB abs., and 117 (67.6\%) positive RF. Anaemia, leukopenia, lymphocytopenia and hypergammaglobulinemia, were significantly more frequent in patients with anti-Ro52 positive abs. The presence of anti-Ro52 abs. was significantly related to the development of lung fibrosis (OR 2.42, $95 \% \mathrm{Cl} 1.23-4.75, \mathrm{p}=0.007$ ), peripheral neuropathy (OR 2.53, 95\% Cl 1.1-5.95,

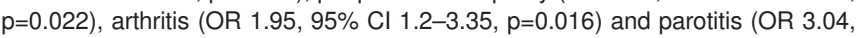
$95 \% \mathrm{Cl} 1.75-5.3, \mathrm{p}<0.001)$. A total of $160 / 173(92.5 \%)$ patients with anti-Ro positive abs. met the EACG criteria. When we analysed the 13 patients with anti-Ro52 positive abs., which did not meet the AECG criteria, these patients presented severe salivary gland scintigraphic involvement, positive ocular test for dry eyes, more hypergammaglobulinemia (OR 6.67, $95 \% \mathrm{Cl} 1.95-22.8, \mathrm{p}=0.003$ ), more peripheral neuropathy (OR $13.8,95 \% \mathrm{Cl} 2.1-92.7, \mathrm{p}=0.0012)$, more lung fibrosis (OR 13.95, 95\% $\mathrm{Cl} 2.1-93.7, \mathrm{p}=0.012$ ), and more risk of lymphoma development (OR $16.72,95 \% \mathrm{Cl} 1.4-199.8, \mathrm{p}=0.039$ ), than patients with suspected SS who did not met the AECG criteria and who had negative anti-Ro52 abs.

Conclusions: in our series most patients with anti-Ro52 positive antibodies had also anti-Ro60/SSA positive antibodies and met the AECG criteria. However, there were 13 patients with positive anti-Ro52 abs., which did not meet the AECG criteria. These patients showed similar characteristics to those with positive antiRo52 abs. and AECG criteria, and had more risk to develop peripheral neuropathy, lung fibrosis and lymphoma. Our results support that anti-Ro52 antibodies should be included in the diagnostic criteria for SS.

Disclosure of Interest: None declared

DOI: 10.1136/annrheumdis-2018-eular.2948

\section{SAT0456 THE INCIDENCE OF CARDIOVASCULAR EVENTS IN ITALIAN PATIENTS WITH SYSTEMIC LUPUS ERYTHEMATOSUS IS LOWER THAN IN NORTH EUROPEAN AND AMERICAN COHORTS: IMPLICATION OF DISEASE-ASSOCIATED AND TRADITIONAL RISK FACTORS AS EMERGED BY A 16-YEAR RETROSPECTIVE GIRRCS STUDY}

S. Fasano ${ }^{1}$, D.P. Margiotta ${ }^{2}$, R. Gualtierotti ${ }^{3}$, A. Corrado ${ }^{4}$, O. Berardicurti ${ }^{5}$, D. lacono ${ }^{1}$, L. Pierro ${ }^{1}$, A. Riccardi ${ }^{1}$, R. Giacomelli ${ }^{5}$, F.P. Cantatore ${ }^{4}$, P. Meroni ${ }^{3}$, A. Afeltra ${ }^{2}, G$. Valentini' on behalf of GIRRCS $=$ Gruppo Italiano di Ricerca in Reumatologia Clinica e Sperimentale. ${ }^{1}$ Division of Rheumatology, Department of Clinical and Experimental Medicine, Università della Campania Luigi Vanvitelli, Naples: ${ }^{2}$ Clinical Medicine and Rheumatology Department, Campus Bio-Medico University of Rome, Rome; ${ }^{3}$ Division of Rheumatology, ASST Pini, Department of Clinical Sciences and Community Health, University of Milan, Milan;

${ }^{4}$ Rheumatology Clinic, Department of Medical and Surgical Sciences, University of Foggia Medical School, Foggia; ${ }^{5}$ Division of Rheumatology, Department of Biotechnological and Applied Clinical Science, University of L'Aquila, L'Aquila, Italy

Background: Cardiovascular (CV) disease is the leading cause of premature death among Systemic Lupus Erythematosus (SLE) patients1. Several studies have analysed the incidence of CV events in SLE patients. However, the majority of them have been conducted in American and North European countries 2-7. At the best of our knowledge, no studies in Italy have considered cumulative incidence and incidence rate of CV events in Italy.

Objectives: The present study is devoted to estimate the incidence of a first ever $\mathrm{CV}$ event in Italian lupus patients from five rheumatologic tertiary units from North, Centre and South Italy and to search for features associated with and potentially causative of the detected differences.

Methods: Clinical charts of SLE patients consecutively admitted to five Italian rheumatologic centres from November 1 st 2000 and December 31 st 2016 were retrospectively studied. Patients selected were free of $\mathrm{CV}$ events at baseline. CV cumulative incidence was evaluated as the proportion of patients who experienced a new CV event over the follow up period. CV incidence rate was expressed as the number of events in the cohort divided by the total number of years at risk. Our incidence was compared with that detected in the Italian general population and those reported in SLE cohorts from other countries.

Results: The median duration of follow-up was 6 years (IQR=3-11). During the observational period, 39 (cumulative incidence $=7.6 \%$ ) of the 511 patients had a first CV event with an incidence rate of 10.4/1000 person-years i.e. 12 times higher than in the general population. The CV cumulative incidence detected in our Italian cohort was similar to that reported in the Spanish cohort, but lower than those from North European and American cohorts. The Italian cohort differed from other SLE cohorts in some traditional risk factors (smoke, hypertension, dyslipidemia) and treatment with aspirin and hydroxychloroquine.(table1)

Abstract SAT0456 - Table 1. Comparison of characteristics among patients from different SLE cohorts (values in bold are statistically significant at an alpha of 0.05 ).

\begin{tabular}{|c|c|c|c|c|c|c|c|}
\hline & $\begin{array}{l}\text { Our } \\
\text { cohort } \\
\mathrm{N}=511\end{array}$ & $\begin{array}{l}\text { Spain } \\
N=3649\end{array}$ & $\begin{array}{l}\text { Sweden" } \\
N=182\end{array}$ & $\begin{array}{l}\text { Ealtimo } \\
r^{2} \\
N=1874\end{array}$ & $\begin{array}{l}\text { PROFLE } \\
N=1333\end{array}$ & $\begin{array}{l}\text { MESAR" } \\
\mathrm{N}=70\end{array}$ & p value \\
\hline Male gender $(n ; \%)$ & $38: 7.1$ & 3539.7 & $18: 10$ & $138: 72$ & $127: 9.8$ & $13: 18.5$ & 0.004 \\
\hline $\begin{array}{l}\text { Age, years } \\
\text { (median, IGR) } \\
\text { (mean, SD) }\end{array}$ & $\begin{array}{l}39 \\
(31-49) \\
45,12.6\end{array}$ & $\begin{array}{l}45 \\
(35-56)\end{array}$ & $\begin{array}{l}45 \\
.31 .53)\end{array}$ & $\begin{array}{l}- \\
37,12\end{array}$ & $\begin{array}{l}- \\
35.7,12.3\end{array}$ & 52 & \\
\hline 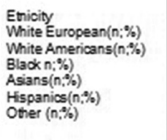 & $\mid \begin{array}{l}511: 100 \\
0 \\
0 \\
0 \\
0 \\
0\end{array}$ & $\begin{array}{l}3300: \\
90.4 \\
185: 5.1 \\
8: 0.2 \\
21 ; 0.6 \\
0 \\
29 ; 0.8\end{array}$ & $\begin{array}{l}171: 94 \\
0 \\
0 \\
11: 6 \\
0 \\
0\end{array}$ & & $\begin{array}{l}0 \\
640: 43.5 \\
472: 35.8 \\
0 \\
241: 18.1 \\
0\end{array}$ & $\mid \begin{array}{l}0 \\
0897 \\
0 \\
0 \\
0 \\
2: 3\end{array}$ & \\
\hline Smokers $(n ; \%)$ & $135: 26.6$ & 1350: & $92 ; 51$ & & 215: 18.1 & $37: 52.9$ & $<0.0001$ \\
\hline Hypertension $(n ; \%)$ & 101:19.9 & $1081 ;$ & $54: 30$ & & $687 ; 51.5$ & 1724 & $<0.0001$ \\
\hline Dyslipidemia (n;\%) & 111: 21.8 & 29.1 & $75: 41$ & & - & $9: 13$ & $<0.0001$ \\
\hline Disbetes $(n ; \%)$ & 16:3.1 & $\begin{array}{l}30.1 \\
179: 49\end{array}$ & $4: 2$ & & - & $5: 7$ & $>0.05$ \\
\hline $\begin{array}{l}\text { HCQ(n;\%) } \\
\text { Aspirin(n; } \% \text { ) }\end{array}$ & \begin{tabular}{|l|}
$431 ; 85.0$ \\
$302 ; 59.5$
\end{tabular} & $\begin{array}{l}2878: \\
78.9 \\
1091: \\
29.9\end{array}$ & $\begin{array}{l}52 ; 29 \\
34 ; 19\end{array}$ & & $\begin{array}{l}1075: 20.6 \\
382: 28.6\end{array}$ & $52 ; 75$ & $\begin{array}{l}<0.0001 \\
<0.0001\end{array}$ \\
\hline$C V$ events $(n ; \%)$ & $39 ; 7.6$ & 269:7.4 & $24: 13$ & 134,7 & $123: 9.8$ & 1724 & $<0.0001$ \\
\hline First CV event & Yes & Yes & Yes & Yes & Yes & No & \\
\hline $\begin{array}{l}\text { Mean bllow-up (years) } \\
\text { Person-years }\end{array}$ & $\begin{array}{l}6 \\
3721\end{array}$ & - & 8.3 & - & 6.4 & $\begin{array}{l}7.7 \\
540\end{array}$ & \\
\hline Incidenoe rate (1000p-y) & 10.4 & 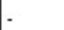 & . & 14.1 & . & 31.4 & \\
\hline
\end{tabular}

Conclusions: Our study confirmed the increased CV risk in SLE compared with the general population. However, the incidence of CV events in our SLE series was lower than that detected in North European and American lupus cohorts. These disparities could be ascribed to the differences in the prevalences of traditional CV risk factors among the distinct cohorts. Nevertheless, our CV cumulative incidence was very similar to that detected in the Spanish cohort, despite their higher frequency of traditional risk factors. For this evidence, the geographic (Mediterranean) origin deserve to be considered. On the other hand, the slight difference detected between our series and Baltimore cohort2(where patients were examined every 3 months) underlines the need of a strict follow-up of the SLE patient.

\section{REFERENCES:}

[1] Cervera R, et al. Medicine (Baltimore) 2003.

[2] Magder LS, Petri M. Am J Epidemiol 2012.

[3] Bertoli AM, et al. Lupus 2009.

[4] Bartels CM, et al. J Rheumatol 2014.

[5] Gustafsson J, et al. Arthritis Res Ther 2009.

[6] Hermansen M-L, et al. Rheumatol Oxf Engl 2017.

[7] Fernández-Nebro A, et al. Medicine (Baltimore) 2015.

Disclosure of Interest: None declared DOI: 10.1136/annrheumdis-2018-eular.1331 